\title{
Evaluating the Spatial and Environmental Benefits of Green Space: An International and Local Comparison on Rural Areas
}

\author{
Luan Cilliers \\ Unit for Environmental Sciences and Management, North-West University, Potchefstroom Campus, South Africa
}

Email address:

luan.cilliers@gmail.com

To cite this article:

Luan Cilliers. Influence Evaluating the Spatial and Environmental Benefits of Green Space: An International and Local Comparison on Rural Areas. Agriculture, Forestry and Fisheries. Special Issue: Planning for Sustainable Communities: Green-Spaces in Rural Areas.

Vol. 4, No. 4-1, 2015, pp. 45-51. doi: 10.11648/j.aff.s.2015040401.16

\begin{abstract}
Many issues exist from isolated planning of urbanized areas and environmental areas. Current approaches focussing on the integration of Urban Planning and Urban Ecology seek to address such issues. Urban Ecology practice aims to describe the study of the joined relationships between humans and nature. Urban Ecology thus forms a major part of Urban and Spatial Planning, with regard to the objectives of sustainable planning and development, green infrastructure planning, and resilience. Green spaces support sustainable human settlements by means of the different benefits which nature provides, referred to in this research as ecosystem services. Green spaces, in this sense, are fundamental areas in human settlements, in need of intentional and structured planning approaches to enhance sustainability and said environmental benefits. Rural settlements in South Africa experience various problems and challenges in terms of planning for the environment through green spaces (as well as sustainability), mainly as a result of the fragmentation of these rural areas, the existence of lost spaces, urbanisation, urban sprawl and poverty. This research attempted to address the challenges of integrated planning and green space provision in a local rural context; evaluated the spatial and environmental benefits of green space; and enhanced the importance of planning for such benefits in rural South African areas. A local and international comparative study was conducted in order to evaluate the green space planning of South African rural areas in terms of international approaches. The comparative study also served as guidance for new green space planning approaches and recommendations in South African rural context.
\end{abstract}

Keywords: Ecosystem Services, Rural Areas, Green Spaces, Green Infrastructure Planning, Resilience

\section{Introduction}

Urbanized environments are often being studied individually and separate from its surrounding natural environment [1]. Current approaches focussing on the integration of Urban Planning and Urban Ecology seek to address these issues of integrated planning. Urban Ecology is an emerging interdisciplinary field that aims to understand how human and ecological processes can coexist in systems dominated by humans and help societies with their efforts to become more sustainable [2].

The term 'urban ecology', because of its unique focus on both humans and natural systems, has been used in various ways to describe the study of (a) humans in human settlements, of (b) nature in human settlements, and of (c) the joined relationships between humans and nature [2].

Studies that aim to enhance environmental planning in urbanized areas have indeed increased over the years internationally, especially by the means of the new effective method, green infrastructure planning [3]. In South Africa however, similar studies were conducted on macro scale and not on specific micro areas that endure specific problems caused by the lack of integration [3]. A lack of such a study on micro scale that addresses specific environmental problems unique to the specific area, thus exist in South Africa. There is also a lack of such a study within rural areas that desperately need change in the way the environmental planning (if any) is conducted.

The environment in human settlements is dependent on the people (in terms of planning and conservation) but the people (society) are also dependent on the environment (in terms of certain benefits which are provided by the said green spaces 
and environment). Human settlements depend on a healthy environment that continuously provides these benefits known as ecosystem services [4]. When the benefits that nature provides in the specific area are identified and the value of these benefits is understood, the movement towards creating a sustainable human settlement can progress even more.

In an attempt to bridge the objectives of Urban Ecology and Spatial Planning, this research aims to evaluate the spatial and environmental benefits of green spaces; and how such spaces can be planned in especially rural areas to enhance the said benefits.

\section{Delineation of Case Studies}

South Africa does not appear to be as evolved in integrating urban and rural areas with the natural environment as is the case internationally [3]. It is thus important for South African Planners to consider the countries which are indeed more evolved and successful in this regard. Following a best practices approach enables local planners to consider strengths and opportunities of an integrated planning approach, while seeking ways to adopt international approaches to fit the local context and challenges.

\subsection{International Case Studies}

Planning in Sweden is conducted from a framework that respects the need to preserve the natural environment [5]. The city of Stockholm is creating policies and using planning in such a way that develops a more sustainable society, a better quality of life for the people, and a quality natural environment [5].

The areas in and around Stockholm were thus selected to serve as international case studies to review, evaluate and compare; thus contributing to the identification of applicable approaches for South Africa. The following two micro case studies in Sweden were studied.

Table 1. International case studies.

\begin{tabular}{lll}
\hline Case study & Type of area & Significance of case study \\
\hline Hågaby & $\begin{array}{l}\text { Eco-village } \\
\text { (rural area) }\end{array}$ & $\begin{array}{l}\text { A resistant, flexible human settlement } \\
\text { integrated with green structures. }\end{array}$ \\
$\begin{array}{l}\text { Hammarby } \\
\text { Sjöstad }\end{array}$ & $\begin{array}{l}\text { Eco-city } \\
\text { (urban area) }\end{array}$ & $\begin{array}{l}\text { Integration of environmental goals in order to } \\
\text { provide a healthier and conserved } \\
\text { environment. }\end{array}$ \\
\hline
\end{tabular}

The reason for the evaluation of a rural and urban area respectively, is to obtain diverse results from diverse area typologies, thus providing diverse planning approaches.

\subsection{Local Case Study}

The Vaalharts area, located in the Northern Cape Province of SA, consists of a beautiful rural landscape with scattered rural settlements and is best known for its water irrigation scheme [6]. The Vaalharts area was thus selected as the local case study as its characteristics represent those of an average rural South African area. The residents in the rural settlements in the Vaalharts area are mainly dependent on the environment (mostly agriculture and water). This contributes to the suitability of this area as the local case study in this research.

Each of the above mentioned international and local areas was firstly studied by means of physical surveys and site analysis, and secondly through structured questionnaires provided to key informants and professionals.

\section{Ecosystem Services}

Parks and other green spaces play multiple roles in making human settlements more sustainable [7]. This is mainly due to the different benefits which nature provide, known as ecosystem services. Parks and green spaces are thus fundamental areas in human settlements that need intentional planning as it provides the opportunity to enhance sustainability and the appearance of environmental benefits [8].

In order to define the concept of ecosystem services, it is important to understand that healthy ecosystems are the foundation of sustainable human settlements and in order for a settlement to be 'healthy' it depends on the natural environment that continuously provides a range of benefits [4]. Ecosystem services are thus the benefits that humans derive directly or indirectly from ecosystem functions.

\subsection{Ecosystem Categories}

Ecosystem services can be divided into four categories, namely Provisioning services, Regulating services, Habitat or supporting services and Cultural services.

\subsubsection{Provisioning Services}

Ecosystem services which are mainly material or energy outputs from ecosystems, such as food, water and medicinal resources [4].

\subsubsection{Regulating Services}

Services provided by regulating the quality of air and soil, or providing flood and disease control [4]. Examples are natural waste-water treatment, erosion prevention and local climate regulation. Fig. 1 illustrates examples of (a) food as provisioning service and (b) wetlands as natural waste-water treatment.

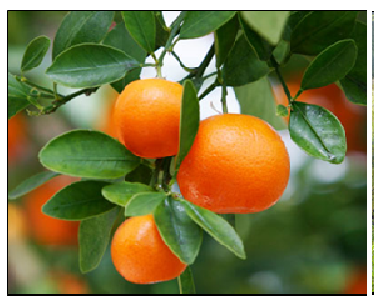

(a)

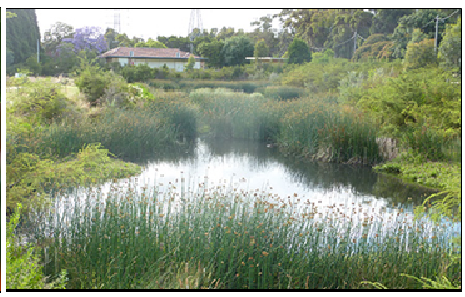

(b)
Figure 1. Provisioning and regulating services.

\subsubsection{Habitat or Supporting Services}

Ecosystems provide living spaces for plants or animals and can also maintain a diversity of plants and animals [4]. 


\subsubsection{Cultural Services}

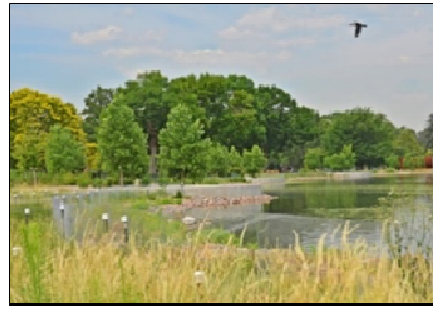

(a)

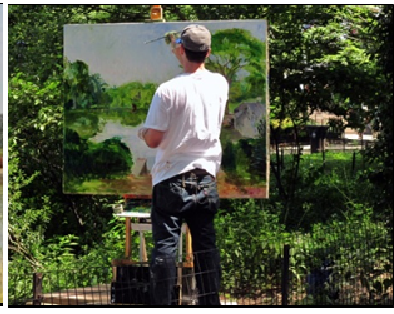

(b)
Figure 2. Habitat/supporting and cultural services.

This is the non-material benefits that people obtain from contact with ecosystems. This includes aesthetic, spiritual and psychological benefits such as physical activities, recreation and tourism [4]. Fig. 2 illustrates examples of (a) a lake as natural habitat and (b) nature as inspiration for aesthetic activities.

\subsection{Providing Ecosystem Services}

An understanding and consideration of ecosystem services is necessary in order to create and maintain a well-planned and managed environment. An integrated planning approach is needed, incorporating green spaces as part of the spatial planning process, referred to as green infrastructure planning [9]; and creating an environment which can respond to change or disturbances and ensure sustainability for future generations, referred to as resilience [10].

Table 2 indicates theoretical principles regarding spatial planning and ecosystem services, which are important to include when planning for green spaces in order to enhance environmental benefits.

Table 2. Theoretical principles in green space planning.

\begin{tabular}{|c|c|}
\hline Principles & Significance \\
\hline $\begin{array}{l}\text { Determining the status } \\
\text { quo of the environment }\end{array}$ & $\begin{array}{l}\text { Ensures an overview of the area's environmental } \\
\text { strengths, weaknesses and opportunities. }\end{array}$ \\
\hline $\begin{array}{l}\text { Focus of the key } \\
\text { stakeholders }\end{array}$ & $\begin{array}{l}\text { The planning focus should include a focus on the } \\
\text { provisioning of ecosystem services }\end{array}$ \\
\hline $\begin{array}{l}\text { Interconnection of } \\
\text { green spaces }\end{array}$ & Ensures no isolation between the green spaces. \\
\hline $\begin{array}{l}\text { Consider green spaces } \\
\text { as green infrastructure }\end{array}$ & $\begin{array}{l}\text { Green spaces receive an equal amount of attention } \\
\text { just as other infrastructure during planning } \\
\text { processes. }\end{array}$ \\
\hline $\begin{array}{l}\text { Providing } \\
\text { multifunctional green } \\
\text { spaces }\end{array}$ & $\begin{array}{l}\text { Green spaces that provide a variety of functions } \\
\text { (heterogenic spaces). }\end{array}$ \\
\hline $\begin{array}{l}\text { Providing different } \\
\text { ecosystem categories }\end{array}$ & $\begin{array}{l}\text { Ensures a variety of ecosystem services and thus a } \\
\text { quality environment. }\end{array}$ \\
\hline
\end{tabular}

Evaluating the planning of green spaces in the international and local case studies in terms of the above mentioned theoretical approaches, indicates a clear link in terms of the provisioning of environmental benefits internationally, while the local South African approach needs to be revised in order to be aligned with theoretical objectives.

\section{Current Challenges in SA}

The current reality of South African rural areas faces a number of environmental challenges. These challenges originate mostly from historic spatial patterns and occurrences in South Africa.

\subsection{Existence of Lost Space}

Lost spaces lead to the existence of deteriorated parks which serve no purpose and are in need of redesign because they make no positive contribution to the surroundings and users [11].

In the local case study of Vaalharts, green spaces are mostly left unplanned and isolated with no vision, usage or maintenance. This contributes to the existence of lost space which provides no environmental benefits.

\subsection{Fragmentation of Human Settlements}

Fragmented settlements encourage people to live isolated lives thus discouraging the use of public green spaces [12]. The Vaalharts area is located far from urban areas which creates a lack of economic activities in order to support planned green spaces. The fragmented environment in terms of human settlements, thus have a negative effect on the planning and maintenance of green spaces.

\subsection{Urbanisation}

Urbanisation pressurises the planning and maintenance of human settlements and especially the green spaces in these settlements [13]. The Vaalharts area is showing an increase in population as more people migrate to the informal human settlements. This could mainly be due to the low living costs in this area as well as the abundance of water and other natural resources. The unplanned green spaces are in effect developed into housing and other infrastructure to fill the growing housing need.

\subsection{Urban Sprawl}

The growing population causes urban sprawl to take place which in turn leads to the fragmentation of natural green spaces as urban sprawl follows no specific growth pattern [14] The problem in the Vaalharts area concerning urban sprawl, is that the informal settlements are growing unplanned and unmaintained, filling the green spaces that had potential for the provisioning of ecosystem services.

\subsection{Poverty}

The need of the poor communities for natural resources causes them to use the natural environment and green spaces in unsustainable ways, thus causing degraded areas [13].

In the Vaalharts area a lack of finances for the planning of green spaces exists. This alludes to a lack of knowledge on ecosystem services. Unsustainable, unplanned and unmaintained green spaces with no specific functions are the result. 


\section{Policies and Legislation}

Policies and legislation are important for the inclusion and guidance of planning for the environment. Fourteen policies and legislation were evaluated, whereof only four indicated a weak level of support for the planning of green spaces. A total of ten policies and legislation indicated a medium to high level of support.

The question however is whether these policies and legislation are comprehensive and sustainable to guide the planning and provision of green spaces in South African rural areas. The White Paper on environmental management policy for SA (1998) was concluded to be one of the policies with the strongest level of support for green spaces that provide environmental benefits specifically in rural areas. Legislation in broad thus supports the integration of the environment through the use of green spaces with urban and rural areas.

It is important to take note that even though the policies and legislation consist of the right focus and aims, it is of great importance that the local communities are informed, educated and involved in order to be able to implement and maintain such approaches. It is thus evident that rural settlements in the Vaalharts area are in need of education and more public participation in terms of environmental planning policy and legislation.

\section{Green Space Planning: International vs. Local Approaches}

Certain gaps exist in the local South African approach to planning and provision of green spaces. Accordingly the local South African approach to planning of green spaces was evaluated by means of a gap-analysis against the international best practices. Table 3 captures the key findings from the site analysis and questionnaires of the international case studies with the local case study.

Table 3. International best practices and gap-analysis in SA.

International best practices
Economic activity of urban centres supports the green spaces.
Direct environments consisting of natural green areas integrate easily
with a settlement's green spaces thus creating more green spaces.
The interconnection of green spaces in settlements.
The planning and design of other aspects such as housing and transport
has an influence on the green spaces.
The conservation of the natural indigenous vegetation and animals when
planning for green spaces is crucial.
Cooperation between various professionals is important when planning
for green spaces.
Variations in the design of elements in the areas contribute to creating
interesting and attractive areas.

It is evident that a number of gaps exist in the green space planning approaches in the Vaalharts area, and ultimately in South Africa. However, a number of strengths can be noted in the Vaalharts area which contributes to its potential of enhancing its provision of ecosystem services. Table 4 lists these strengths.

\section{Table 4. Strengths in the local case study.}

Vaalharts is situated in an area rich in natural green areas and indigenous vegetation as well as animals.

The area is highly accessible.

A variety of land use types exist in the area.

Residents of the settlements in the area are dependent on the environment. Cooperation of different professionals within the planning process exists.

The abundance of water ensures the provision of sustainable green spaces The Vaalharts area has potential to support ecosystem services.

\section{Planning Recommendations}

Recommendations are made to provide new and innovative approaches to planning for the environment in rural areas in South Africa. These recommendations thus focus on proposing approaches which (a) comply with suitable

\section{Gap-analysis in the Vaalharts area}

Green spaces are not situated near economic activities as few economic activities exist in the rural settlements.

The environments directly bordering the rural settlements are mostly natural green areas with indigenous vegetation. Potential thus exists for the integration of green spaces.

Most green spaces are isolated from each other, but the rivers flowing through a few of the settlements cause some interconnection of green spaces to occur.

Green spaces are not integrated with the surroundings and are planned isolated from the surroundings.

The green spaces in the Vaalharts area consist mostly of natural indigenous vegetation as well as animals (in the game reserves).

A strength exists in the cooperation of a variety of professionals in order to plan for a more sustainable area.

Green spaces appear to be mostly homogeneous. theoretical approaches, as well as best practice approaches found in international case studies; and (b) enhance and provide different ecosystem service types from the different ecosystem categories within local rural areas. The recommendations are discussed subsequently.

\subsection{Shifting the Focus to Ecosystem Services}

The education of municipalities, key stakeholders and residents on the importance of ecosystem services, is the starting point to a shift in the focus when planning for settlements.

A method that was used in the international case study of Hammarby Sjöstad, is the education of residents by the use of placing educational information signs along the green spaces. These educational signs inform the residents on unique environmental qualities in the specific area. This can be incorporated with hiking trails and other recreational activities in green spaces. This approach can be implemented within the local rural context of South Africa as well. Fig. 3 illustrates such information boards in the international case studies. 


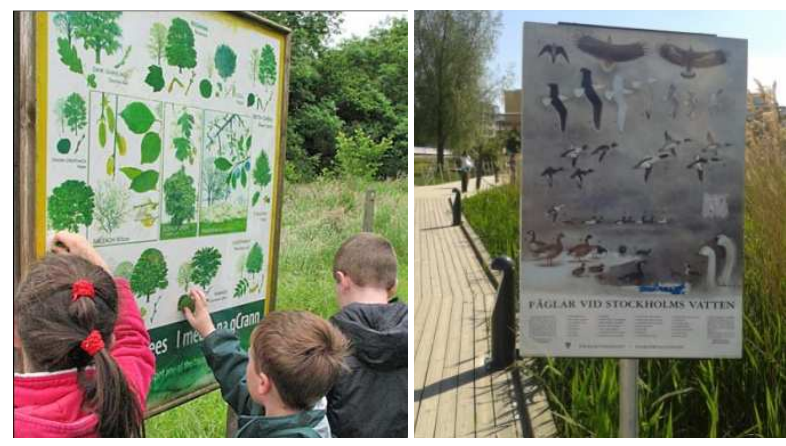

Figure 3. Educational information signs in parks.

\subsection{Interconnecting Green Spaces}

The rivers and streams running through the Vaalharts area provide opportunity for interconnected green spaces as the rivers physically connect the green spaces. The interconnected green spaces along the rivers and streams should be planned in an integrated manner in order to enhance activities and services such as recreation, conservation of the natural environment and storm water management. A green-avenue that was planned along the canals in the international case study is a best practice example of transforming canals (which created lost spaces along the sides of the canals) to interconnected green spaces that provide benefits and activities to the surrounding areas. Fig 4 illustrates green spaces that formed along canals or natural rivers.

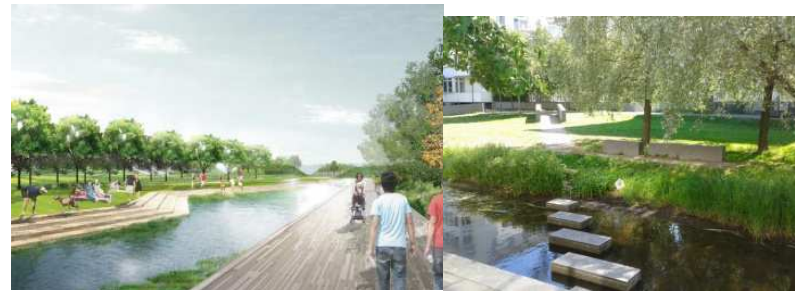

Figure 4. Green-avenues planned along canals.

\subsection{Integrating Green Spaces with Surroundings}

The green spaces in the Vaalharts area need to be planned according to specific functions which it can provide to the specific surrounding communities within the area. Green spaces located nearby schools and residential areas (accommodating large numbers of children), can be functionally integrated with the surrounding area by planning the green space with a focus which will attract children. The international case studies were found to be located mainly in areas with high numbers of young families and children. Green spaces were thus planned mostly as playgrounds and sport facilities in order to functionally integrate the green spaces to the surrounding communities.

\subsection{Providing a Variety of Ecosystem Services}

As the quality of the natural environment in the Vaalharts area has great potential to provide environmental benefits, it is recommended that provisioning is made for ecosystem services from all four the ecosystem categories. This ensures that a variety of ecosystem services are provided, addressing a great variety of the community's needs.

\subsubsection{Provisioning Services}

It is recommended that parts of the green spaces situated within the residential areas of the rural settlements are planned for the provisioning of food to the local communities. As the poor communities live in settlements of high density, every housing unit does not have its own backyard and thus need space for their own food production. It is thus recommended that community gardens be implemented in parts of the green spaces. Fig. 5 illustrates an example of a community garden in the international case study.

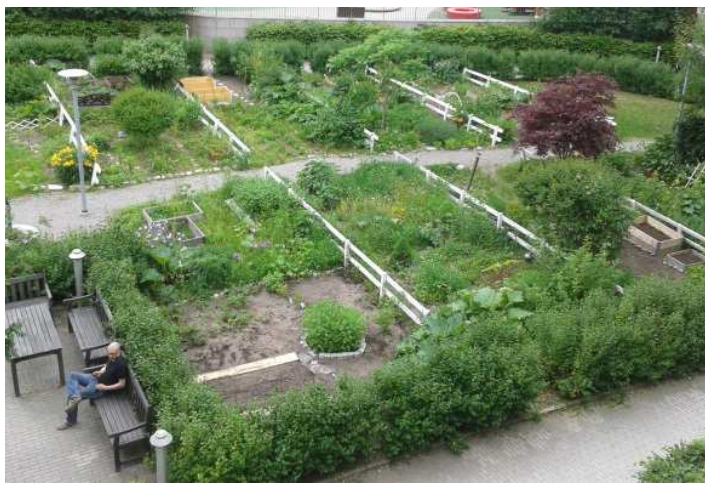

Figure 5. A community garden for residents with no private garden.

\subsubsection{Regulating Services}

The regulation of storm water in the Vaalharts area can be enhanced through the planning and provision of ecosystem services. The natural vegetation, including the soil, act as filters of water, breaking down waste in water through biological activities as the water flows through vegetated areas. It is thus recommended that built water drainage pipes along the roads be incorporated with the natural environment by removing parts of the built concrete pipes in order to ensure that the storm water flows through vegetated areas as well to filter the water. The water thus has to be directed towards the green spaces where it can be absorbed by trees and plants, or directed to water sources such as dams or streams in the green spaces, as in the cases of the international case studies. Fig. 6 illustrates how storm water is directed to green spaces and canals in the international case study.

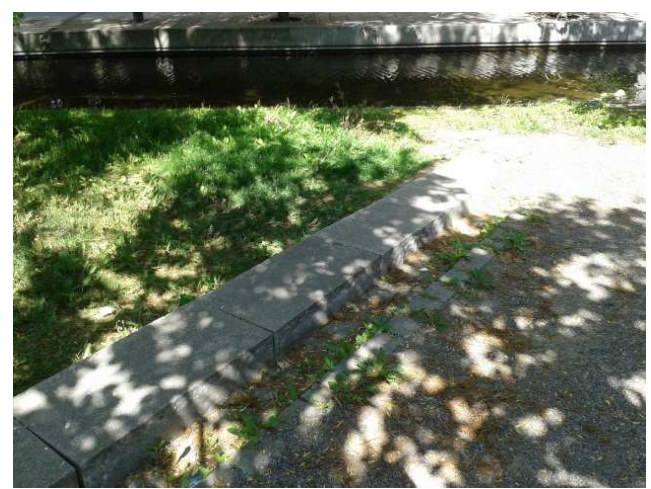

Figure 6. A Storm water drainage system directed to a green space and canal. 


\subsubsection{Habitat or Supporting Services}

This area's natural environment is considered a great habitat for African wildlife as a number of nature reserves exist within the area. It is recommended that current protected nature reserves which are located close or adjacent to human settlements be integrated with these settlements' green spaces. This creates a continuous habitat spreading throughout the entire Vaalharts area (This recommendation only considers small mammals, insects and birds that cannot be kept in by fences). Integrating the nature reserves with the settlement's green spaces was proven to be successful in the international case studies. This was done through the development of informative hiking trails stretching from the settlements' green spaces toward the nature reserves.

\subsubsection{Cultural Services}

Tourist activities should be integrated with green spaces in settlements. This can be done by using the green spaces as special markets or festivals on occasional days in order to sell agricultural products unique to the Vaalharts area. This enhances the usage of green spaces and ensures opportunities to inform tourists on the natural environment. This also provides economic benefits which brings a vital source of income to the Vaalharts area through the usage of the natural environment. The international case study of Hågaby used this method, thus creating an awareness among the tourists about the importance of the environment as well as sustainable living.

Recreational activities such as hiking trails can be implemented to contribute to the residents' mental as well as physical health, and to create an aesthetic appreciation in the area. Fig. 7 illustrates a unique recreational hiking trail that was implemented in the international case study.

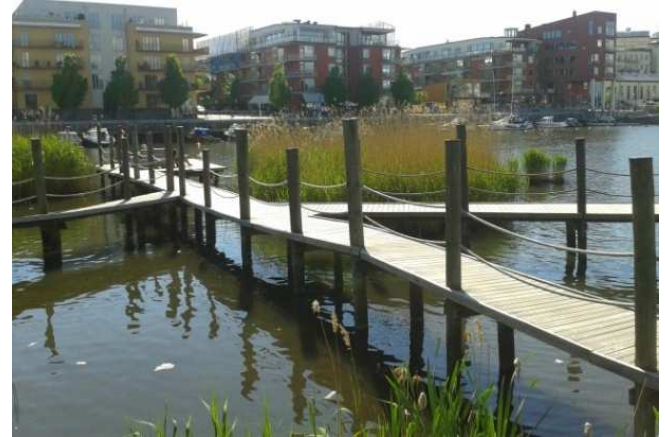

Figure 7. A hiking trail developed along a water source in Hammarby Sjöstad.

The sustainability of these recommended approaches is greatly dependent on the cooperation of the local communities, local authorities and professionals involved in the planning process.

\section{Conclusion}

International approaches of planning for green spaces in order to enhance the provisioning of environmental benefits can be adopted locally in SA. This paper highlights that the following two issues are of great importance in the planning of green spaces to provide environmental benefits in the local South African context: (1) a unique green planning approach can be created for the specific area's characteristics and (2) a team of key role players understanding the importance and role of green spaces within the spatial planning reality should be involved. An integrated area (urbanized or rural) which provides environmental benefits to the community, while simultaneously conserving the natural environment can thus be created.

Table 5 captures the summative conclusions based on the evaluation of the spatial and environmental benefits of green space provision.

Table 5. Spatial and environmental benefits of green space.

\begin{tabular}{|c|c|c|}
\hline d in the study & Spatial benefits & Environmental benefits \\
\hline $\begin{array}{l}\text { Educating people on the importance of } \\
\text { environmental benefits. }\end{array}$ & $\begin{array}{l}\text { Expands the knowledge and insight regarding } \\
\text { sustainability included in the spatial planning } \\
\text { process. }\end{array}$ & Enhancement of residents' quality of life \\
\hline Interconnection of green spaces. & $\begin{array}{l}\text { Creates lively, open and accessible areas for the } \\
\text { community. }\end{array}$ & $\begin{array}{l}\text { Provides recreational activities, conservation of the natural } \\
\text { environment and storm water management }\end{array}$ \\
\hline $\begin{array}{l}\text { Green spaces regarded as part of a } \\
\text { settlement's infrastructure. }\end{array}$ & $\begin{array}{l}\text { Spatially integrated, quality areas which are } \\
\text { accessible }\end{array}$ & $\begin{array}{l}\text { Regulation of storm water from urban infrastructure to } \\
\text { green spaces which provides filtered water. }\end{array}$ \\
\hline Multifunctional spaces. & $\begin{array}{l}\text { Encourages mixed land uses as well as accessibility } \\
\text { amongst different uses }\end{array}$ & $\begin{array}{l}\text { Different activities such as gardens for food provisioning, } \\
\text { recreational activities (hiking), educational activities } \\
\text { (school tours), economic activities (shops and restaurants) } \\
\text { and social activities are enhanced through the green } \\
\text { spaces. }\end{array}$ \\
\hline $\begin{array}{l}\text { Integration of green spaces with } \\
\text { surroundings. }\end{array}$ & $\begin{array}{l}\text { Spatially integrated areas that are open and } \\
\text { accessible }\end{array}$ & $\begin{array}{l}\text { Enhances the usage and functions of green spaces as well } \\
\text { as the quality of life, in especially poor communities. }\end{array}$ \\
\hline $\begin{array}{l}\text { Conservation of indigenous plants and } \\
\text { animals in settlements. }\end{array}$ & $\begin{array}{l}\text { Creates spatially attractive areas. Conserving nature } \\
\text { influences the areas' functions and thus the physical } \\
\text { structure of settlements }\end{array}$ & $\begin{array}{l}\text { Provides a source of income for the area; purifies flowing } \\
\text { water, healthier air quality, and habitats for animals }\end{array}$ \\
\hline
\end{tabular}

An integrated area (urbanized or rural) which provides environmental benefits to the community, while simultaneously conserving the natural environment can thus be created when a focus is placed on the achievement of spatial and environmental benefits. 


\section{Acknowledgements}

This research (or parts thereof) was made possible by the financial contribution of the NRF (National Research Foundation) South Africa. Any opinion, findings and conclusions or recommendations expressed in this material are those of the author and therefore the NRF does not accept any liability in regard thereto.

\section{References}

[1] M.M. McConnachie and C.M. Shackleton, "Public green space inequality in small towns in South Africa," Grahamstown: Department of Environmental Science, Rhodes University, 2012.

[2] J.M. Marzluff, E, Shulenberger and E. Endlicher., "Urban ecology: an international perspective on the interaction between humans and nature," New York: Springer, 2008.

[3] A. Schäffler and M. Swilling, "Valuing green infrastructure in an urban environment under pressure: the Johannesburg case," Ecological Economics, vol. 86, pp. 246 - 257, 2013.

[4] TEEB, "The economics of ecosystems \& biodiversity: ecosystem services in urban management," USA, 2011, http://www.teebweb.org/Portals/25/Documents/TEEB_Manual for_Cities_Ecosystem_Services_for

Urban_Management_FINAL_2011.pdf. (Accessed 1 $\overline{\text { February 2014). }}$

[5] A. Nelson, "Stockholm, Sweden: city of water," Sweden, 2006, http://depts.washington.edu/open2100/Resources/1_OpenSpac eSystems/Open_Space_Systems/Stockholm_Case_Study.pdf, (Accessed 12 June 2014).
[6] S.P.R. Labuschagne, J. Van Loggerenberg and J.H. Lombard, "The Role of GIS to Identify Nodes and Guide Sustainable Development in Rural Areas," Potchefstroom: NWU. (Mini-dissertation - Hons), 2013.

[7] J. Byrne and N. Sipe, "Green and open space planning for urban consolidation - A review of the literature and best practice," Brisbane: Griffith University, 2010.

[8] Commission for Architecture \& the Built Environment, "Start with the park: creating sustainable urban green spaces in areas of housing growth and renewal," London: Cabe Space, 2011.

[9] U.G. Sandström, on green infrastructure planning in urban Sweden, Planning Practice \& Research, vol. 17(4), pp. 373-385, 2002.

[10] J. Ahern, "From fail-safe to safe-to-fail: Sustainability and resilience in the new urban world," Landscape and Urban Planning, pp. 341-343, 2011.

[11] R. Trancik, "Finding lost space: Theories of urban design," Boston: John Wiley \& sons, 1986.

[12] J. Barnett, "The fractured metropolis: Improving the new city, restoring the old city, reshaping the region," New York: Harper Collins, 1995.

[13] Department of Environmental Affairs and Tourism, "South Africa environment outlook: A report on the state of the environment," Pretoria: Department of Environmental Affairs and Tourism, 2006.

[14] J.B. McMahan, K.T. Weber and J.D. Sauder, "Using remotely sensed data in urban sprawl and green space analysis," Intermountain Journal of Science, vol. 1(8), pp. 30 - 37. 